\title{
Psicologia Escolar e possibilidades na atuação do psicólogo: Algumas reflexões
}

\author{
Ana Cristina Garcia Dias \\ Universidade Federal de Santa Maria - RS \\ Naiana Dapieve Patias \\ Universidade Federal de Santa Maria - RS \\ Josiane Lieberknecht Wathier Abaid \\ Centro Universitário Franciscano
}

\begin{abstract}
Resumo
A Psicologia Escolar, área tradicional da profissão de psicólogo no Brasil, sofre diversas críticas referentes ao modo como são conduzidas determinadas práticas em seu contexto, por isso necessita ser constantemente repensada e discutida. O presente artigo propõe uma reflexão sobre a Psicologia Escolar e sua(s) possibilidades de atuação. Inicialmente realiza-se uma contextualização histórica sobre a Psicologia Escolar, com a observação de que esse é um campo ainda em construção no Brasil. Em um segundo momento, busca-se elucidar alguns aspectos que hoje tornam a Psicologia Escolar uma área específica e de grande importância na atuação do psicólogo. Por fim, discute-se a necessidade tanto de o psicólogo atuar com os diferentes atores presentes no contexto educacional quanto de trabalhar de forma interdisciplinar na escola e em qualquer outro ambiente no qual sejam desenvolvidos processos de ensino-aprendizagem.
\end{abstract}

Palavras-chave: Psicologia Escolar, história da psicologia, atuação do psicólogo.

\section{School psychology and possibilities for the psychologist work: some reflections}

\begin{abstract}
School psychology, a traditional area of psychology in Brazil, has been criticized due to the manner psychological knowledge is being applied in educational contexts, which entails continued reflection on and rethinking of its role in these contexts. In this paper we propose a critical analysis of the possibilities of School Psychology. First, the historical background of School Psychology is presented, pointing out that this is a field yet in construction in Brazil. Second, aspects that make School Psychology an important and specific area of intervention for psychologists are highlighted. Finally, we discuss the need for psychologists to interact with the different actors present in the educational context, as well as working in an interdisciplinary way in schools and other environments where teaching-learning processes are developed.
\end{abstract}

Key-words: School psychology, history of psychology, psychologist performance.

\section{Psicología Escolar y posibilidades en la actuación del psicólogo: algunas reflexiones}

\begin{abstract}
Resumen
La psicología escolar, área tradicional de la profesión del psicólogo en Brasil, posee diversas críticas referentes a cómo son conducidas determinadas prácticas en su contexto, por lo tanto necesita ser constantemente repensada y discutida. Este artículo propone una reflexión sobre la Psicología Escolar y su(s) posibilidad(es) de actuación. Inicialmente se realiza una contextualización histórica sobre la Psicología Escolar señalándose que se trata de un campo aún en construcción en Brasil. En la segunda etapa se busca aclarar algunos aspectos que hoy hacen que la Psicología Escolar sea un área específica y de gran importancia en la actuación del psicólogo. Finalmente, se discute la necesidad del psicólogo actuar tanto con los diferentes actores presentes en el contexto educacional como trabajar de forma interdisciplinar en la escuela y en cualquier otro ambiente en el que sean desarrollados procesos de enseñanza aprendizaje.
\end{abstract}

Palabras Clave: Psicología escolar, historia de la psicología, actuación del psicólogo. 


\section{Introdução}

No Brasil, a Psicologia Escolar ${ }^{1}$, enquanto área de atuação do psicólogo, tem enfrentado uma série de dificuldades e contradições. Essa área é quase tão antiga em nosso país quanto a profissão de psicólogo (Guzzo, 2001); porém as práticas realizadas pelos psicólogos escolares vêm sendo constantemente objeto de críticas, por serem consideradas inadequadas e insatisfatórias nas suas respostas às questões educacionais e escolares desenvolvidas no Brasil (Guzzo, Mezzalira, Moreira, Tizzei, \& Silva Neto, 2010).

$\mathrm{Na}$ prática, além de muitos profissionais atuarem de maneira equivocada, priorizando o foco na Psicopatologia Clínica, no aluno ou em sua família, percebe-se que os profissionais da Educação (professores, supervisores escolares, orientadores pedagógicos) e familiares não compreendem ou ainda desconhecem o que faz o psicólogo escolar (Cassins e cols., 2007; Gaspar \& Costa, 2011). Isso pode ser atribuído às questões históricas relacionadas ao próprio desenvolvimento da Psicologia Escolar em nosso país. Historicamente, a Psicologia Escolar buscou aplicar os conhecimentos de psicologia aos problemas de aprendizagem e de comportamento dos alunos, realizando um acompanhamento psicológico e vocacional, além do treinamento de professores (Bock, 2003; Cassins e cols., 2007; Gaspar \& Costa, 2011; Souza, 2007; Souza, Ribeiro \& Silva, 2011). De fato, por muito tempo o psicólogo inserido no contexto educacional utilizou como principal ferramenta no contexto escolar os testes psicológicos, com o intuito de medir as capacidades e habilidades dos alunos e neles identificar possíveis problemas e psicopatologias (Cassins e cols., 2007; Machado \& Souza, 2004).

Essa forma de atuação do psicólogo, que prioriza medidas e diagnósticos clínicos, foi motivo de controvérsias dentro e fora da Psicologia. A partir da década de 1980 surgiram críticas a essas práticas psicológicas realizadas no contexto escolar, pois elas apresentavam uma visão reducionista do indivíduo e dos processos que ocorrem no contexto escolar/educacional. Por um lado, era preciso conhecer e classificar o aluno para auxiliá-lo no melhor desempenho da aprendizagem. Em contrapartida, era necessário ter em mente que os problemas enfrentados pelo aluno na escola não decorriam exclusivamente de fatores individuais ou de seu ambiente próximo. Era necessário questionar processos, práticas, ideologias e questões políticas presentes no contexto educacional e social que referendavam e contribuíam para o desenvolvimento do fracasso escolar em certos grupos socioeconômicos e culturais (Patto, 2004).

Dessa forma, o psicólogo inserido na escola deve buscar o aperfeiçoamento de suas práticas mediante intervenções que considerem fatores históricos, sociais, políticos e econômicos, realizando uma intervenção ampla e contextualizada, que envolva os diferentes atores presentes nos

1 Neste trabalho utilizaremos apenas o termo Psicologia Escolar referindo-se a Psicologia Escolar e Educacional, pois as autoras compartilham da ideia de que não há como separar esses termos, uma vez que se complementam. processos educativos, sejam eles professores, pais, funcionários, alunos - enfim, a comunidade escolar (Gaspar \& Costa, 2011; Guzzo, 2002); contudo, ainda hoje se percebe uma concomitância de modelos de atuação nas práticas desenvolvidas pelos psicólogos escolares/educacionais, uma vez que são desenvolvidas tanto práticas que preservam características de propostas mais tradicionais e excludentes quanto práticas inovadoras e transformadoras dos indivíduos e instituições educacionais (Martinez, 2010).

Considera-se que ainda há muito a discutir sobre a atuação do psicólogo nas escolas, uma vez que esta ainda é uma área pouco conhecida, se comparada às áreas de clínica e organizacional (Marinho-Araújo \& Almeida, 2005). Do mesmo modo, é problemática a forma como os indivíduos percebem a atuação do psicólogo, ou mesmo a formação acadêmica ofertada na área. Ainda permanece no imaginário social que o psicólogo deve atender os alunos problemáticos, remediar situações conflituosas e "apagar incêndios", desenvolvendo práticas clínicas individuais (Patias, Monte Blanco, \& Abaid, 2009). De fato, ainda encontramos no exercício dos psicólogos nas escolas intervenções reducionistas e individualizantes, que centram suas práticas apenas em atendimentos clínicos a alunos, seus familiares ou os professores (Gaspar \& Costa, 2011; Souza e cols., 2011; Teixeira, 2003). Este trabalho pretende discutir algumas implicações dessas formas de atuação do psicólogo, indicando alguns aspectos que podem ser modificados para que o psicólogo possa auxiliar nos processos educativos presentes nos contextos educacionais.

\section{Um pouco da história da Psicologia Escolar}

A atuação da Psicologia Escolar no país ocorreu concomitantemente ao desenvolvimento da Psicologia enquanto ciência. Inicialmente, observou-se uma grande preocupação com a quantificação dos fenômenos psíquicos. Desta forma, no início do século passado o psicólogo escolar encontrava-se mensurando os fenômenos psíquicos junto aos laboratórios das escolas de educação e de filosofia (Bock, 2003; Guzzo, 2002; Marinho-Araújo \& Almeida, 2005; Patto, 1997; Souza, 2007). Sua atuação era predominantemente associada à prática da psicometria e ao desenvolvimento de intervenções clínicas individuais em instituições de ensino. A causa dos problemas educacionais estava centrada no aluno, ao passo que fatores externos - sociais, econômicos, políticos, institucionais, históricos e pedagógicos - eram ignorados (Cassins e cols., 2007; Teixeira, 2003). O principal objetivo era resolver os problemas escolares (Meira \& Antunes, 2003), sobretudo, o temido "fracasso escolar".

O psicólogo escolar, nesse paradigma, era apenas um psicometrista, que avaliava as crianças indicando em que áreas essas apresentavam dificuldades. Sua atuação nesse período apresentava um caráter clínico-terapêutico que buscava "consertar" a criança e "adaptá-la" ao contexto escolar (Barbosa \& Marinho-Araújo, 2010; Bock, 2003; Guzzo e cols., 2010). Os testes, os laudos e os diagnósticos, 
que se constituíam nas principais formas de atuação do psicólogo escolar, "explicavam" aos profissionais presentes no contexto escolar e aos leigos, os motivos do fracasso escolar de determinado aluno. Ao utilizar essas técnicas, muitas vezes o psicólogo acabava por tentar corrigir o "aluno-problema” (ou sua família), a fim de readaptá-lo ao sistema escolar. Dessa forma, a responsabilidade pelas dificuldades que se apresentavam no sistema educacional era sempre depositadas no aluno e/ou em sua família (Andrada, 2005; Barbosa \& Marinho-Araújo, 2010; Guzzo, 2002; Guzzo e cols., 2010). Nesses momentos iniciais, todos os problemas escolares, tanto o referentes à não aprendizagem como os pertinentes a problemas comportamentais, eram atribuídos aos alunos-problema ou então às suas famílias, consideradas, "desestruturadas" ou "incapazes" (Marinho-Araújo \& Almeida, 2005).

Patto (1997, 2004), com suas ideias revolucionárias, apontou que a Psicologia Escolar não poderia se ocupar mais com teorias e práticas reprodutivas do status quo, sem considerar o papel social da escola na formação do cidadão. Essa autora descreveu no livro "A produção do Fracasso Escolar" como a Psicologia Escolar estava a serviço de uma ideologia que servia para excluir e estigmatizar os indivíduos e suas famílias, dividindo e classificando os alunos entre os que aprendiam e os que não aprendiam. Essa divisão encontrava-se predominantemente baseada na divisão de classes (Patto, 1997, 2004).

\section{Como é hoje e (ou) como poderia ser?}

Embora a atuação do psicólogo escolar tenha se modificado, continua apresentando-se problemática, tanto em função do sistema educacional brasileiro (que está distante das condições de excelência no ensino) como pela formação oferecida aos futuros profissionais da Psicologia que atuarão nesse campo. A formação geralmente é deficiente e não contempla as especificidades presentes nos processos educacionais e no contexto escolar (Guzzo, 2001; Guzzo e cols., 2010).

A literatura especializada utiliza diferentes denominações para se referir ao psicólogo que atua junto às escolas e aos processos educacionais, principalmente as de psicólogo escolar e psicólogo educacional. O primeiro psicólogo, o escolar, seria aquele que, atuando diretamente na escola, ocupa-se das questões práticas a ela referentes, enquanto o segundo, o psicólogo educacional, seria aquele ocupado em pensar, refletir e pesquisar sobre os processos educacionais em geral. Este seria uma espécie de produtor de conhecimentos a serem utilizados pelos psicólogos escolares (Guzzo, 2001; Marinho-Araújo \& Almeida, 2005). Apesar dessa diferenciação de termos, atualmente diversos autores (Andrada, 2005; Patto, 1997, 2004) não concordam com essa divisão, pois consideram que o psicólogo escolar ou educacional é aquele que se ocupa tanto da prática como do pensar sobre os processos educacionais, estando esses presentes ou não no contexto escolar. Segundo essas autoras, é preciso pensar em um psicólogo que se ocupe dos processos educacionais ao longo da vida, uma vez que estes não ocorrem apenas no contexto escolar, nem se encontram restritos a alguma etapa especifica do desenvolvimento humano.

Embora não seja um pré-requisito para atuar na área, atualmente um psicólogo pode obter seu reconhecimento como especialista na área de Psicologia Escolar/Educacional a partir da realização de uma prova realizada pelo Conselho Federal de Psicologia para concessão de titulo, ou mediante a realização de um curso de especialização reconhecido pelo referido Conselho. Para habilitar-se para a prova o profissional deve apresentar alguns critérios exigidos pelo CFP, como estar inscrito no Conselho Regional de Psicologia há pelo menos dois anos, comprovar prática profissional na área escolar e educacional por pelo menos dois anos (CFP, 2007).

Essa área foi reconhecida como uma especialidade pelo Conselho Federal de Psicologia (CFP) através da Resolução n. ${ }^{\circ}$ 013/07. Nesse sentido, o CFP descreve algumas tarefas que cabem a esse campo de atuação do psicólogo. $\mathrm{Na}$ descrição das atividades, podem ser observados alguns aspectos que descrevem e qualificam a atuação do psicólogo escolar, propondo um trabalho interdisciplinar e integrado aos contextos educacionais, que pode ser desenvolvido tanto individualmente como em grupo, em diferentes níveis, como promoção, prevenção e tratamento. Segundo o Conselho Federal de Psicologia (2007, p.18), o psicólogo

Nessa tarefa, considera as características do corpo docente, do currículo, das normas da instituição, do material didático, do corpo discente e demais elementos do sistema. Em conjunto com a equipe, colabora com o corpo docente e técnico na elaboração, implantação, avaliação e reformulação de currículos, de projetos pedagógicos, de políticas educacionais e no desenvolvimento de novos procedimentos educacionais. No âmbito administrativo, contribui na análise e intervenção no clima educacional, buscando melhor funcionamento do sistema que resultará na realização dos objetivos educacionais.

De acordo com a Resolução 013/07 do CFP, cabe ao psicólogo escolar ocupar-se de um amplo leque de possibilidades que se referem diretamente ao âmbito do ensino-aprendizagem, tanto em seu contexto formal (escola, instituições de ensino) quanto no informal (organizações não governamentais, empresas, etc.). O psicólogo escolar/educacional trabalha os processos educacionais que acontecem tanto com crianças e adolescentes como com pessoas adultas ou mais maduras. Exemplos disso são os programas de acompanhamento psicopedagógico e educacionais realizados no ensino de jovens e adultos (EJA), nas escolas técnicas, nas universidades e nos programas de universidades para a terceira idade (Bonai \& Thiers, 2006). Além desses contextos, o psicólogo que se ocupa dos processos educacionais hoje pode atuar junto a organizações não governamentais (ONGs), programas de treinamento 
em empresas, hospitais, associações comunitárias ou qualquer outro local onde ocorram esses processos de ensino e aprendizagem; porém é necessário que o psicólogo centre seu foco de atenção nos processos educacionais, especialmente nas condições de ensino e aprendizagem, para que sua atuação não se confunda com a realizada por outros psicólogos que também atuam nestas instituições, com diferentes focos (organizacional, hospitalar) (Marinho-Araújo \& Almeida, 2005; Patto, 1997). Esse profissional deve atuar de forma interdisciplinar, juntamente com a equipe que trabalha com os processos educacionais nas instituições de educação, como educadores especiais, pedagogos, etc. - e fora delas, mas que podem fazer parte de uma rede de atenção aos indivíduos, famílias e comunidades - como assistentes sociais, secretarias de educação, de saúde, e outros órgãos públicos) (Cassins e cols., 2007). Em sua atuação o psicólogo não pode se esquecer das questões econômicas e políticas envolvidas nesses processos de ensino-aprendizagem

Assim, ser psicólogo escolar ou educacional no Brasil exige conhecer as necessidades das pessoas no que se refere aos processos educacionais, não importando o contexto ou as condições sociais ou políticas em que estejam inseridas (ricas, pobres, capacitadas, deficientes, abandonadas ou acolhidas por suas famílias (Almeida e cols., 1995). O psicólogo busca defender os direitos do indivíduo no atendimento de suas necessidades educacionais e promover seu desenvolvimento, sem discriminação ou intolerância de qualquer tipo ou grau, tendo o cuidado de não reproduzir formas de dominação. Neste sentido, é preciso que o psicólogo tanto se encontre inserido no contexto no qual esses processos ocorrem como conheça aspectos históricos, econômicos, políticos e culturais da população e da comunidade que atende. Para isso, ele precisa: a) atuar em uma equipe multidisciplinar; b) estar constantemente estudando e participando de eventos da área e trocando experiências com os pares; c) sair do gabinete para olhar a realidade tal como ela se apresenta, confusa e inexplicável, fora de controle e desafiadora (Cassins e cols., 2007). Este profissional deve conscientizar-se de que há muito trabalho pela frente e muitas formas de realizar esses trabalhos. Nessa caminhada, ele pode apresentar diferentes sentimentos, especialmente diante da urgência e emergência de diferentes demandas presentes no contexto escolar, uma vez que deverá estar preparado para realizar o que ainda não está pronto e necessita ser construído (Almeida e cols., 1995), mas precisa estar atento tanto às necessidades da população que atende como às suas potencialidades na realização de um trabalho conjunto.

De fato, pesquisadores indicam a necessidade de a atuação do psicólogo escolar se efetuar no local em que os fenômenos ocorrem, para que ele não se aliene (Cabral \& Sawaia, 2001; Martinez, 2010). Apesar disso, ainda hoje é possível encontrar muitos "psicólogos escolares" que se ocupam de problemas de aprendizagem, de desvios de comportamento apresentados no contexto escolar a partir de atividades realizadas apenas em seus consultórios, sem conhecer as realidades e as condições nas quais estas questões se produzem (Martinez, 2010).
Outro aspecto importante, que parece ser um consenso em estudos na área, é que nos processos educativos o psicólogo escolar não pode apenas trabalhar com práticas curativas ou patologizantes, mas deve se ocupar tanto com a prevenção quanto com a promoção do desenvolvimento dos agentes envolvidos no processo educativo, estando atendo às potencialidades apresentadas pelos diferentes atores presentes nos contextos educacionais (Gaspar \& Costa, 2011; Lessa \& Facci, 2011; Souza e cols., 2011).

Por outro lado, Rodrigues, Itaborahy, Pereira, \& Gonçalves (2008), em pesquisa realizada com 23 psicólogos escolares de Juiz de Fora (MG), perceberam dificuldades no desenvolvimento e concretização de novas práticas focadas na promoção e prevenção. Na pesquisa desenvolvida, que teve como objetivo investigar concepções e práticas desses psicólogos sobre prevenção e promoção de saúde, os autores constataram que há deficiências na formação, predominando o enfoque curativo.

Valle (2003) considera que o psicólogo deve mudar seu foco de atuação no contexto escolar, passando de um enfoque clínico e remediativo, no qual sua atuação centra-se na solução de problemas, para um enfoque preventivo ou voltado para a promoção de saúde. Os processos de ensino-aprendizagem devem envolver ações que estimulem o desenvolvimento dos indivíduos (desenvolvimento de habilidades, competências, etc.) e dos grupos. Assim, o foco de trabalho desloca-se para os fatores de proteção e de promoção de saúde e resiliência, sendo trabalhados aspectos de prevenção primária, voltados à população geral, não apenas às populações vulneráveis.

Algumas pesquisas apontam ser possível encontrar práticas dos psicólogos escolares que atendam a essas novas exigências e atribuições. Exemplo disso encontramos no trabalho desenvolvido por Loos e Zeller (2007). Esses autores relataram uma experiência de intervenção realizada em uma escola pública municipal, cujo objetivo foi o treinamento de habilidades sociais e de interação interpessoal, o que contribuiu para minimizar os episódios agressivos frequentes na escola. Essa forma de intervenção contribui para afirmar a identidade do "novo" psicólogo escolar, que se dedica à comunidade escolar por meio de intervenções preventivas em grupo.

O psicólogo escolar vem atuando de diferentes formas, além de realizar algumas atividades já criticadas, como a clínica e a avaliação de alunos e professores. Os psicólogos vêm promovendo grupos de discussão e outras formas de atendimento que não se centram apenas em práticas avaliativas ou clínica terapêutica. Patias, Monte Blanco e Abaid (2009), por exemplo, desenvolveram oficinas com professores trabalhando a expressão de ideias, sentimentos e atitudes em relação ao trabalho com os alunos. Essa experiência, segundo as autoras, permitiu a criação, além do espaço físico, de um espaço psicológico, para que se percebessem as dificuldades e os potenciais do grupo de professores e alunos. Houve uma melhora nas habilidades e na comunicação entre a equipe diretora e os professores. 
De fato, alguns estudos indicam a necessidade de a Psicologia Escolar trabalhar com os diferentes atores envolvidos no contexto educacional da escola. Por exemplo, é importante trabalhar com alunos, professores, pais, merendeiras, funcionários da limpeza, diretores - enfim, com todos aqueles que se encontrem, de uma forma ou de outra, envolvidos nesse contexto educativo, uma vez que a educação não é apenas realizada em sala de aula (Marinho-Araújo \& Almeida, 2005).

Da mesma forma, faz-se necessário que o psicólogo escolar conheça os indivíduos e os contextos em que atua, com suas histórias, culturas e especificidades. É preciso conhecer a realidade a partir da análise de diferentes dimensões, com a histórica, a cultural, a política e outras, para que o conhecimento produzido possa explicar a complexidade dos fenômenos e oferecer subsídios concretos para a realização de intervenções eficazes. A Psicologia, nesse sentido, deve assumir uma dimensão crítica e política, apresentando uma preocupação constante com a realidade social imediata (Guzzo e cols., 2010).

Uma possível teoria a ser utilizada para compreender os indivíduos nos processos educacionais é a Teoria Bioecológica, desenvolvida por Bronfenbrenner e Morris (1998). Essa teoria busca considerar os contextos e processos dos indivíduos através do tempo. A Teoria Bioecológica do Desenvolvimento Humano permite pensar a escola como um microssistema no qual há relações de diversas pessoas que desempenham papéis diferenciados no desenvolvimento de seus membros. Essa teoria ressalta a importância de trabaIhar com diferentes atores, considerando diferentes níveis de relações e processos, compreendendo como esses se influenciam mutuamente (Bronfenbrenner, 2011).

Outra teoria importante que vem sendo utilizada e desenvolvida por diferentes autores que trabalham com a Psicologia Escolar no Brasil é a Psicologia histórico-cultural e teórico-crítica (Vygotsky, 1999). Essa perspectiva defende que o desenvolvimento humano ocorre através de processos de mediação simbólica desencadeados pelas trocas de experiências entre os indivíduos nas suas relações sociais. Neste sentido, as competências humanas são desenvolvidas nas relações sociais surgidas da mediação de instrumentos de natureza concreta e simbólica, sendo que a escola representa um papel fundamental no desenvolvimento dessas competências nos indivíduos (Marinho-Araújo \& Almeida, 2005).

Almeida (2001), ao falar das teorias e da atuação do psicólogo escolar, afirma que na formação é preciso redimensionar as diferentes teorias psicológicas, ampliando-as e integrando-as a outras referências teóricas e metodológicas, especialmente observando as contribuições de cada uma para a área da Educação. Na atuação prática é importante uma reflexão crítica sobre as teorias psicológicas que tenha como pano de fundo suas origens ideológicas. Para a autora, as práticas psicológicas que orientam a atuação profissional serão necessariamente requalificadas se apoiadas em teorias que enfatizem tanto os fatores objetivos e subjetivos do contexto sociocultural como as relações inter e intrassubjetivas dos atores envolvidos nos processos educativos.

Hoje se percebem na literatura psicológica preocupações com o caráter político e transformador que o psicólogo escolar deve apresentar e considerar ao exercer sua prática (Guzzo e cols., 2010; Rodrigues e cols., 2008). Mais que um compromisso político, é um compromisso ético que esse profissional deve desenvolver. O psicólogo escolar está trabalhando com diferentes indivíduos (crianças, adolescentes, adultos, idosos) em diferentes condições de desenvolvimento, em contextos ditos "normais" e/ou "especiais".

Assim, percebe-se que em sua atuação o psicólogo escolar se preocupa com a consideração dos processos institucionais que estão produzindo formas de subjetivação nos diferentes atores e no desenvolvimento dos processos educacionais. Como indicado anteriormente, a literatura referente à Psicologia Escolar traz uma preocupação ética muito grande com a atuação do psicólogo. Nesse sentido, alguns autores (Guzzo, 2001; Patto, 1997; Rodrigues e cols., 2008) apontam que o psicólogo escolar, além de desenvolver atividades práticas de maneira crítica, deve atuar como um pesquisador e reprodutor de conhecimentos.

Guzzo (2001) indica que há muito a ser investigado e produzido nessa área, principalmente em relação a modelos de atuação para a realidade brasileira. A autora indica que frequentemente a atuação do psicólogo escolar se mostra descontextualizada, pois os modelos são importados de outros países.

No Brasil, na tentativa de garantir atendimento de psicólogos e assistentes sociais em instituições de educação pública básica, foi proposto o Projeto de Lei 3.688, apresentado na Câmara dos Deputados no ano de 2000. Desde então o referido projeto sofreu diversas alterações e emendas e tramitou no Senado Federal como o Projeto de Lei Complementar PLC 60/2007, que foi aprovado nessa instância em 2010 e aguarda a sanção presidencial. O projeto dispõe sobre a prestação de serviços de psicologia e de assistência social nas escolas públicas de atenção básica aproveitando-se os serviços da rede, de forma a não sobrepor atendimentos. Assim não estabelece, como disposto no projeto inicial de 2000 , a obrigatoriedade da presença destes profissionais no quadro de funcionários da escola, até porque não haveria como custear isso. Mesmo que as proposições legais sejam aprovadas de forma lenta, fica claro que a atuação do psicólogo escolar é cada vez mais demandada, principalmente devido aos conflitos que têm emergido das relações, muitas vezes perversas e violentas, que ali se estabelecem. Além, disso, o fluxo estressante da atividade dos professores os leva a necessitar ainda mais de intervenções psicológicas que produzam revisão de suas práticas disciplinares e educativas. Resta perguntar até que ponto esse quadro estimula graduados em Psicologia a desejarem especializar-se na área escolar.

Um estudo realizado nos Estados Unidos com mais de trezentos graduados em Psicologia que atuavam na área escolar revelou que sua motivação principal pela área era a preferência pelo trabalho com crianças, entre outras ex- 
periências pessoais vivenciadas no âmbito escolar (Graves \& Wright, 2007). Assim, o problema da baixa procura dos graduandos pela área não é exclusividade do Brasil, o que demonstra que esta área deve receber investimentos por parte das políticas públicas governamentais e não governamentais.

\section{Considerações finais}

Para concluir, considera-se que o campo da Psicologia Escolar ou Educacional encontra-se em consolidação. É necessário utilizar os conhecimentos psicológicos já adquiridos e buscar novos conhecimentos dentro da própria Psicologia e em outros domínios, como a Educação, as Sociologia, a Filosofia, etc., com vista a uma atuação que trabalhe com a complexidade apresentada pelos processos de ensino-aprendizagem em suas dimensões históricas e políticas.

O psicólogo não deve ser aquele que traz um saber ou uma resposta pronta; ele vai interagir com os demais atores para construir uma solução viável dentro do contexto da Educação, tanto na escola quanto na universidade ou em uma organização não governamental. Nesse processo, é importante que o psicólogo construa uma postura crítica e criativa e esteja aberto aos múltiplos desafios e possibilidades presentes nos contextos educacionais. Para isso, é necessário que haja investimento na formação desses profissionais, desde a graduação, de forma a capacitá-los a exercer uma psicologia que promova as qualidades apontadas.

\section{Referências}

Almeida, S. F. C. (2001). O Psicólogo Escolar e os Impasses da Educação: Implicações da(s) Teoria(s) na Atuação Profissional. Em Z. Del Prette (Org). Psicologia Escolar e Educacional, saúde e qualidade de Vida (pp. 43-57). Campinas, SP: Alínea.

Almeida, S. F. C. e cols. (1995). Concepção e Práticas do Psicólogo Escolar Acerca das Dificuldades de Aprendizagem. Psicologia: Teoria e Pesquisa 11(2), 117- 134.

Andrada, E. G. C. (2005). Novos Paradigmas na prática do psicólogo escolar. Psicologia Reflexão e Crítica, 18(2), 196-199.

Barbosa, R. M., \& Marinho-Araújo, C. M. (2010). Psicologia escolar no Brasil: considerações e reflexões históricas. Estudos de Psicologia (Campinas), 27(3), 393-402.

Bock, A. M. B. (2003). Psicologia da educação: cumplicidade ideológica. Em M. E. M. Meira \& M. A. M. Antunes (Orgs.), Psicologia escolar: Teorias críticas (pp.79-103). São Paulo: Casa do Psicólogo.

Bonai, Z., \& Thiers, V. (2006). Fatores psicológicos na produção textual em alunos de educação de jovens e adultos. Recuperado:
10 jan 2011. Disponível: http://www.psicologia.pt/artigos/ver_ artigo.php?codigo $=\mathrm{A} 0274 \&$ area $=\mathrm{d} 3 \&$ subarea $=$

Bronfenbrenner, U. (2011). Bioecologia do desenvolvimento humano: tornando os seres humanos mais humanos. Porto Alegre, Artmed.

Bronfenbrenner, U., Morris, P. A. (1998). The ecology of developmental processes. Em W. Damon \& R. M. Lerner (Orgs.), Handbook of child psychology, Vol. 1: Theoretical models of human development (pp. 993-1028). New York: John Wiley.

Cabral, E., \& Sawaia, S. M. (2001). Concepções e atuação profissional diante das queixas escolares: os psicólogos nos serviços públicos de saúde. Estudos de Psicologia, 6(2), 143-1551.

Cassins, M. e cols. (2007). Manual de Psicologia escolar-educacional. Conselho Regional de Psicologia do Paraná. Curitiba: Gráfica e Editora Unificado.

Comissão de Constituição e justiça e cidadania. (2011). Projeto de Lei $n^{\circ} 3.688$ de 2000. Brasília, DF.

Conselho Federal de Psicologia (CFP) (2007). Resoluções relativas ao Título Profissional de Especialista em Psicologia e dispõe sobre normas e procedimentos para seu registro $n^{\circ} 013 / 07$. Recuperado: 07 jan 2011. Disponível: http://www.pol.org.br/pol/export/sites/ default/pol/legislacao/legislacaoDocumentos/resolucao2007_13.pdf

Gaspar, F. D., \& Costa, T. A. (2011). Afetividade e atuação do psicólogo escolar. Revista Semestral da Associação Brasileira de Psicologia Escolar e Educacional, 15(1), 121-129.

Guzzo, R. S. L. (2001). Formando Psicólogos Escolares no Brasil: Dificuldades e Perfectivas. Em S. M. Weschler (Org.), Psicologia Escolar: Pesquisa, Formação e Prática (p. 92). Campinas, SP: Alínea.

Guzzo, R. (Org). (2002). Psicologia Escolar: LDB e educação hoje. São Paulo: Alínea.

Guzzo, R., Mezzalira, A., Moreira, A., Tizzei, R., \& Silva Neto W. (2010). Psicologia e Educação no Brasil: uma visão da história e possibilidades nessa relação. Psicologia.: Teoria e Pesquisa, 26, 131-141.

Graves, J., \& Wright, L. (2007). Comparison of individual factors in school psychology graduate students: why do students pursue a degree in school psychology? Psychology in the schools, 44(8), 865-872.

Lessa, P. V., \& Facci, M. G. (2011). A atuação do psicólogo no ensino público do Estado do Paraná. Revista Semestral da Associação Brasileira de Psicologia Escolar e Educacional, 15(1), 131-141.

Loos, H., \& Zeller, T. J. V. (2007). Aprendendo a "Brigar Melhor": administração de Conflitos sem Violência na Escola. Interação em Psicologia, 11(2), 281-289. 
Machado, A. M., \& Souza, M. P. R. (Org). (2004). Psicologia Escolar: em busca de novos rumos. São Paulo: Casa do Psicólogo.

Marinho-Araújo, C., \& Almeida, S. (2005). Psicologia Escolar: Construção e consolidação da identidade profissional. Campinas, SP: Alínea.

Martinez, A. M. (2010). O que pode fazer o psicólogo na escola? Em Aberto, 23(83), 39-56.

Meira, M. E. M., \& Antunes, M. A. M. (Org). (2003). Psicologia Escolar: teorias críticas. São Paulo: Casa do Psicólogo.

Patias, N. D., Monte Blanco, M. H., \& Abaid, J. L. W. (2009). Psicologia Escolar: proposta de intervenção com professores. Cadernos de Psicopedagogia (UNISA) 7(13), 42-60.

Patto, M. H. S. (Org). (1997). Introdução à psicologia escolar (3a ed.). São Paulo: Casa do Psicólogo.

Patto, M. H. S. (2004). A produção do fracasso escolar. São Paulo: Casa do Psicólogo.
Rodrigues, M. C., Itaborahy, C. Z., Pereira, M. D., \& Gonçalves, T. M. (2008). Prevenção e promoção de saúde na escola: concepções e práticas de psicólogos escolares. Gerais: Revista Interinstitucional de Psicologia, 1(1), 67-78.

Souza, M. P. R. (2007). A Psicologia Escolar e o ensino de psicologia: Dilemas e perspectivas. ETD - Educação Temática Digital, 8(2), 258-265.

Souza, C. S., Ribeiro, M. J., \& Silva, S. M. (2011). A atuação do psicólogo escolar na rede particular de ensino. Revista Semestral da Associação Brasileira de Psicologia Escolar e Educacional, 15(1), 53-61.

Teixeira, P. (2003). Psicólogo Escolar: esse desconhecido. Revista Eletrônica de Psicologia, 2, 1-4.

Valle, L. E. L. R. (2003). Psicologia Escolar: Um duplo desafio. Psicologia: Ciência e Profissão, 23(1), 22-29.

Vygotsky, L. S. (1999). Teoria e método em psicologia (2a ed.). São Paulo, SP: Martins Fontes.

Recebido em: 24/07/2012

Aprovado em: 19/10/2012

\section{Sobre as autoras}

Ana Cristina Garcia Dias (anacristinagarciadias@gmail.com)

Professora do Programa de Pós-graduação em Psicologia da Universidade Federal de Santa Maria (UFSM), Doutora em Psicologia (USP/SP).

Naiana Dapieve Patias (naipatias@hotmail.com)

Mestre em Psicologia (UFSM), Doutoranda em Psicologia (UFRGS).

Josiane Lieberknecht Wathier Abaid (josianelieb@yahoo.com.br)

Professora no Curso de Psicologia do Centro Universitário Franciscano (UNIFRA), Mestre e Doutoranda em Psicologia (UFRGS). 
